\title{
Back pain : a randomized clinical trial of rotational manipulation of the trunk
}

\author{
J. R. GLOVER, JEAN G. MORRIS', and T. KHOSLA
}

Welsh National School of Medicine, Department of Social and Occupational Medicine, Heath Park, Cardiff CF4 4XN

\begin{abstract}
Glover, J. R., Morris, Jean G., and Khosla, T. (1974). British Journal of Industrial Medicine, 31, 59-64. Back pain: a randomized clinical trial of rotational manipulation of the trunk. A therapeutic trial was conducted in a medium-sized engineering works on patients suffering from back pain with its accompanying tenderness and hyperaesthesia. The patients were randomly allocated to two treatment groups, $(a)$ manipulation, and $(b)$ de-tuned (i.e., simulated) short-wave diathermy, the latter acting as a placebo. The manipulated group were given one lumbar rotational manipulation session of 15 minutes or less and this was followed by four daily detuned short-wave diathermy sessions of 15 minutes. The control group were given five 15-minute daily sessions of detuned short-wave diathermy only. The patients' own subjective assessment of relief from pain was recorded in the range $0 \%$ (no relief) to $100 \%$ (complete relief). The responses were measured at three stages, (1) within 15 minutes, (2) three days after treatment, and (3) seven days after treatment. Although each of the two treatment groups showed progressive and marked improvement in the percentage of relief from pain during the seven-day period, there was no demonstrable difference between the two, except that at the 15-minute stage the relief from pain in the manipulated group was always greater than in the controls.
\end{abstract}

We have been unable to trace any previous report of a randomized clinical trial of manipulation for back pain. This is undoubtedly in part because back pain has so many different and not always definable causes. It is possible, however, to define a syndrome consisting of (1) back pain, (2) skin hyperaesthesia, (3) tenderness, and (4) limitation of trunk movement in one or more directions by pain (Glover, 1960) which not only delineates the vertebral level of the pain but also distinguishes between bilateral and unilateral pains. There appears to be only one other published therapeutic trial of the physical treatment of this type of pain; it concerned neck pain and was carried out by the British Association of Physical Medicine (1966), but manipulation was not included in the various forms of treatment used.

${ }^{1}$ Radiographer and physiotherapist, late of Westinghouse Brake and Signal Co. Ltd.
None of the treatments included in that trial appeared to have any advantage over the others.

It is impossible to carry out a double-blind clinical trial comparing manipulation with any of the other orthodox or unorthodox treatments of back pain, for both the doctor and the patient will know which of the treatments (traction, massage, exercise, injection, infrared short-wave diathermy, or bedrest) have been allocated. The best that can be done in the way of a randomized trial is to have an observer, who does not know which treatment has been given, assessing the results independently of the therapist. Some of those treatments, such as exercise, massage, and infrared short-wave diathermy, might, if applied too rigorously, make the back pain worse and therefore artificially enhance the effect of manipulation. In the trial which we describe here, detuned (i.e., simulated) short-wave diathermy, in which the lights of the diathermy 
machine are on, the timer is clicking, but no current is flowing nor are the tissues being warmed, is used as the control treatment and compared with rotational manipulation of the lower back.

\section{Method}

\section{Pool of cases}

All patients with back pain occurring between the inferior angle of the scapula and the lower end of the sacrum, reporting to the works medical centre over a period of 15 months, were considered for the trial (200 cases). It was decided to exclude patients who:

(1) had bilateral areas of pain and hyperaesthesia. We needed unilateral cases because $(a)$ the contralateral side was required for comparison, and (b) if bilateral cases had been manipulated on each side it would have been impossible for the patients to differentiate the two residual pains accurately (116 cases);

(2) were already under the treatment of another doctor (no cases); or

(3) were found to have abnormal radiological or neurological signs that would contraindicate manipulation (no cases).

This left 84 individuals for inclusion in the trial.

\section{Random allocation}

The patients were divided into those who $(a)$ were in the first attack of back pain, and $(b)$ had previously had one or more attacks of back pain. These two groups were then subdivided into those who had had their pain for less than a week, and those who had had pain for more than a week. Within each of these four subgroups, patients were allocated to the manipulation or control series in accordance with a prearranged sequence for that subgroup, based on random sampling numbers and contained in a numbered set of sealed envelopes.

\section{Procedure}

Each patient's history was taken and coded; his back was radiographed and a specific neurological examination of the lower limb to exclude lumbar or sacral nerve root pressure was carried out. The area of skin hyperaesthesia (Glover, 1960) was outlined in red. Deep tenderness was recorded in kilograms (Glover, 1966) by pressing vertically downwards on the most tender spot in the pain area with a pressure gauge $(1 \cdot 2 \mathrm{~cm}$. $(0 \cdot 5$ in) diameter spherical head) at the approximate rate of increase of $1 \mathrm{~kg}$ per second. The test was stopped at $10 \mathrm{~kg}$, as beyond this point bruising may ultimately occur. The normal human back (and in this trial the opposite side of the back was normal by selection) can stand, under these test conditions, a force of $10 \mathrm{~kg}$ without a feeling of tenderness. Straight leg raising and forward flexion were also measured in degrees from the horizontal and vertical axes respectively. Hyperaesthesia and tenderness were mapped out and recorded at each stage to make sure that we were still dealing with the original pain area and to ensure that the patient was not describing a new area of pain at a different vertical level or on the opposite side.

If the patient was found to be suitable for the trial he was placed on a low wooden couch between detuned diathermy electrodes, and the physiotherapist, who was to be the 'blind' observer, left the building for 15 minutes. Only then did one of us (J.R.G.) take the next random allocation card out of the sealed envelope in the appropriate subgroup. If it indicated no manipulation, the trial was simply discussed with the patient. At 15 minutes the electrodes were taken away, the machine was switched off, and the patient was asked to stand at the side of the couch ready for the physiotherapist's return. If, on the other hand, the random card indicated manipulation, the electrodes were taken away, the patient was turned with his affected side uppermost, and a rotational manipulation of the lower spine and sacrum was carried out until the area of hyperaesthesia had begun to diminish. If there was no diminution of the area of hyperaesthesia after 15 minutes no further manipulation was attempted. In either case the patient was then asked to stand by the couch and not to mention the manipulation but only to use the word 'treatment'.

The physiotherapist, who had been trained for three years on how to map out hyperaesthesia and measure the other signs, entered the room wearing a radiologist's red visual shield. This prevented her from seeing the red line which outlined the pretreatment hyperaesthesia and any red wheals left by the pin drag in mapping it out. She mapped out and measured the residual hyperaesthesia and the remaining tenderness.

She then asked the patient about his pain. Was it better, the same, or worse than before the treatment? If better or worse, the present pain was recorded as a percentage of the original pain. The correlation between the percentage of pain and the other signs which were used to make sure we were assessing the same pain at the same level at each stage, namely, skin hyperaesthesia, deep tenderness, restriction of straight leg raising or forward flexion of the trunk by pain, will be given in a later paper.

\section{Follow-up}

The physiotherapist then gave every patient detuned short-wave diathermy for four days. On the third and seventh days and at one month, she measured all the signs and assessed the percentage of residual pain with the patient. All 84 cases were followed up for one month or more.

Eighty-four patients were allocated to four categories based on the presence or absence of each of the four following criteria: first attack; one or more previous attacks; pain for less than seven days; or pain for seven or more days.

Each patient was subsequently randomly allocated to either manipulation or short-wave diathermy, giving rise finally to eight treatment groups (Table 1).

\section{Results}

Only 11 female patients could be included in the trials, and, as there was no statistically significant difference between the relief of pain in males and females, the results are reported for both sexes combined. In the comparisons, two of the manipulated groups were on average older by seven years 
TABLE 1

Mean Age within Control and Manipulation Groups by SeX and Duration of Pain

\begin{tabular}{|c|c|c|c|c|c|c|c|c|}
\hline \multirow{2}{*}{$\begin{array}{l}\text { No. of } \\
\text { attacks }\end{array}$} & \multirow{2}{*}{ Duration of pain } & \multirow{2}{*}{ Treatment group } & \multicolumn{2}{|c|}{ Sex } & \multirow{2}{*}{$\begin{array}{l}\text { Total } \\
\text { nos. }\end{array}$} & \multirow{2}{*}{$\begin{array}{c}\text { Mean } \\
\text { age }\end{array}$} & \multirow{2}{*}{$\begin{array}{l}\text { Range of } \\
\text { age }(y r)\end{array}$} & \multirow{2}{*}{$\begin{array}{l}\text { Line } \\
\text { no. }\end{array}$} \\
\hline & & & $M$ & $F$ & & & & \\
\hline \multirow{2}{*}{ First } & $<7$ days & $\begin{array}{l}\text { Control } \\
\text { Manipulation }\end{array}$ & $\begin{array}{r}11 \\
8\end{array}$ & $\overline{1}$ & $\begin{array}{r}11 \\
9\end{array}$ & $\begin{array}{l}35 \\
34\end{array}$ & $\begin{array}{l}22-50 \\
21-63\end{array}$ & $\begin{array}{l}1 \\
2\end{array}$ \\
\hline & $\geqslant 7$ days & $\begin{array}{l}\text { Control } \\
\text { Manipulation }\end{array}$ & $\begin{array}{l}4 \\
7\end{array}$ & $\begin{array}{l}2 \\
1\end{array}$ & $\begin{array}{l}6 \\
8\end{array}$ & $\begin{array}{l}32 \\
39\end{array}$ & $\begin{array}{l}16-56 \\
19-55\end{array}$ & $\begin{array}{l}3 \\
4\end{array}$ \\
\hline \multirow{2}{*}{2 or more } & $<7$ days & $\begin{array}{l}\text { Control } \\
\text { Manipulation }\end{array}$ & $\begin{array}{r}11 \\
9\end{array}$ & $\begin{array}{l}1 \\
3\end{array}$ & $\begin{array}{l}12 \\
12\end{array}$ & $\begin{array}{l}40 \\
47\end{array}$ & $\begin{array}{l}20-59 \\
27-59\end{array}$ & $\begin{array}{l}5 \\
6\end{array}$ \\
\hline & $\geqslant 7$ days & $\begin{array}{l}\text { Control } \\
\text { Manipulation }\end{array}$ & $\begin{array}{l}10 \\
13\end{array}$ & $\begin{array}{l}2 \\
1\end{array}$ & $\begin{array}{l}12 \\
14\end{array}$ & $\begin{array}{l}41 \\
43\end{array}$ & $\begin{array}{l}29-56 \\
26-64\end{array}$ & $\begin{array}{l}7 \\
8\end{array}$ \\
\hline
\end{tabular}

than their respective controls (lines 3 and 4: lines 5 and 6, Table 1) but these differences are not of great importance.

Table 2 gives the mean values of the relief of pain recorded at three points in time: (1) immediately after the treatment, (2) three days after the treatment, and (3) seven days after the treatment. The response to treatment was assessed subjectively on a percentage scale from $\mathbf{0}$ (no relief from pain) to $100 \%$ (complete relief), as reported by the patient himself. The mean values of the responses show a progressive improvement with time. By the seventh day seven subgroups (lines 1 to 7 ) had shown considerable improvement ( $70 \%$ to $93 \%$ relief).
Figures 1 to 5 show the mean responses in some of the comparisons.

Except for the comparison (Fig. 2) between the responses of the manipulated and control groups immediately after treatment, none of the other differences was significant at the conventional 0.05 level. The trends in favour of the manipulated group shown in Fig. 2, however, are not consistently observed in two other comparisons (Figs 1 and 3). Although each of the two treatment groups showed progressive and marked improvement in the relief from pain over the seven-day period, there is no evidence of a consistent difference between the treatments. Tests of significance on ranked differ-

TABLE 2

Subjective Assessment of Relief from Pain

\begin{tabular}{|c|c|c|c|c|c|c|c|}
\hline \multirow{2}{*}{$\begin{array}{l}\text { No. of } \\
\text { attacks }\end{array}$} & \multirow{2}{*}{$\begin{array}{c}\text { Duration of } \\
\text { pain }\end{array}$} & \multirow{2}{*}{\multicolumn{2}{|c|}{ Treatment group }} & \multicolumn{3}{|c|}{$\%$ Mean pain relief ${ }^{2}$} & \multirow{2}{*}{$\begin{array}{l}\text { Line } \\
\text { no. }\end{array}$} \\
\hline & & & & $\begin{array}{l}\text { Imme- } \\
\text { diately } \\
\text { after }\end{array}$ & 3 days & 7 days & \\
\hline \multirow{2}{*}{ First } & $<7$ days & $\begin{array}{l}\text { Control } \\
\text { Manipulation }\end{array}$ & $\begin{array}{r}11^{1} \\
9^{1}\end{array}$ & $\begin{array}{l}12 \\
43\end{array}$ & $\begin{array}{l}42 \\
61\end{array}$ & $\begin{array}{l}70 \\
85\end{array}$ & $\begin{array}{l}1 \\
2\end{array}$ \\
\hline & $\geqslant 7$ days & $\begin{array}{l}\text { Control } \\
\text { Manipulation }\end{array}$ & $\begin{array}{l}6 \\
8\end{array}$ & $\begin{array}{l}18 \\
22\end{array}$ & $\begin{array}{l}53 \\
42\end{array}$ & $\begin{array}{l}74 \\
73\end{array}$ & $\begin{array}{l}3 \\
4\end{array}$ \\
\hline \multirow{2}{*}{2 or more } & $<7$ days & $\begin{array}{l}\text { Control } \\
\text { Manipulation }\end{array}$ & $\begin{array}{l}12 \\
12\end{array}$ & $\begin{array}{l}33 \\
33\end{array}$ & $\begin{array}{l}69 \\
65\end{array}$ & $\begin{array}{l}88 \\
93\end{array}$ & $\begin{array}{l}5 \\
6\end{array}$ \\
\hline & $\geqslant 7$ days & $\begin{array}{l}\text { Control } \\
\text { Manipulation }\end{array}$ & $\begin{array}{l}12 \\
14\end{array}$ & $\begin{array}{l}21 \\
36\end{array}$ & $\begin{array}{l}57 \\
34\end{array}$ & $\begin{array}{l}85 \\
53\end{array}$ & $\begin{array}{l}7 \\
8\end{array}$ \\
\hline 1 or more & $\begin{array}{c}\text { Combined histories } \\
\text { of pain }\end{array}$ & $\begin{array}{l}\text { Control } \\
\text { Manipulation }\end{array}$ & $\begin{array}{l}41 \\
43\end{array}$ & $\begin{array}{l}22 \\
34\end{array}$ & $\begin{array}{l}56 \\
50\end{array}$ & $\begin{array}{l}80 \\
75\end{array}$ & $\begin{array}{r}9^{3} \\
10^{4}\end{array}$ \\
\hline
\end{tabular}

${ }^{1}$ Number of patients

2Patient's own assessment of pain relief recorded in the range $0 \%$ (no relief) to $100 \%$ (complete relief). The mean pain relief is based on the percentage pain relief of each patient

${ }^{8}$ Lines $1,3,5$, and 7 combined

LLines 2, 4, 6, and 8 combined 


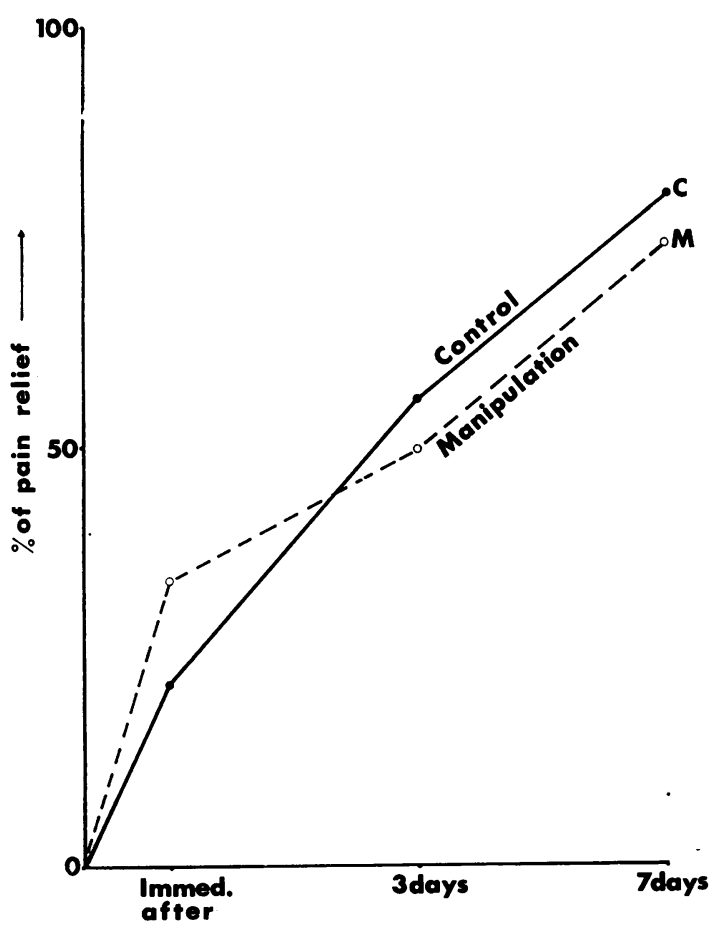

FIG. 1. Relief of pain in control and manipulated groups (Table 2, lines 9 and 10).

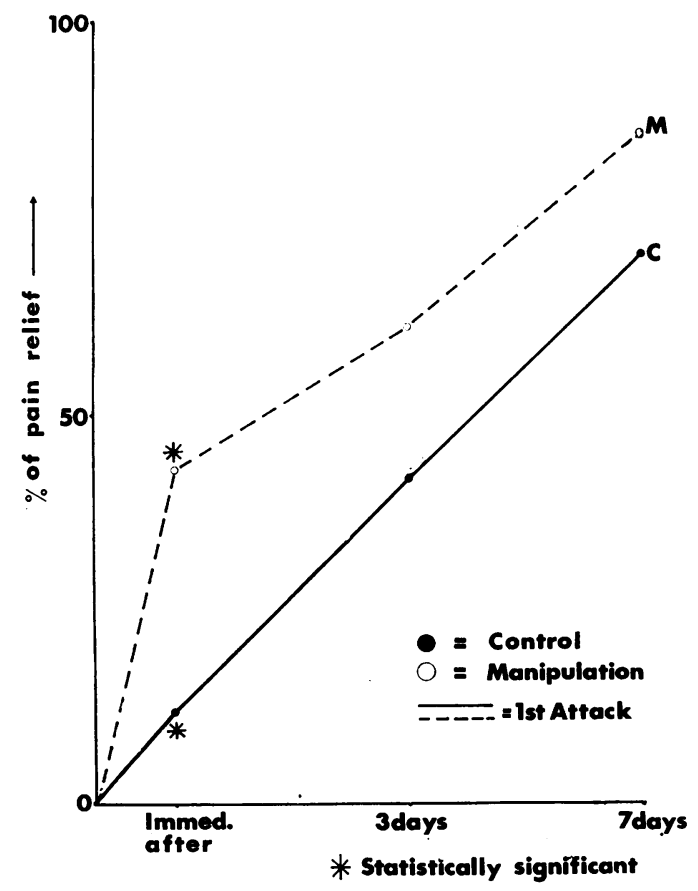

FIG. 2. Relief of pain in patients in their first attack which had lasted less than seven days at the time of treatment (Table 2, lines 1 and 2).

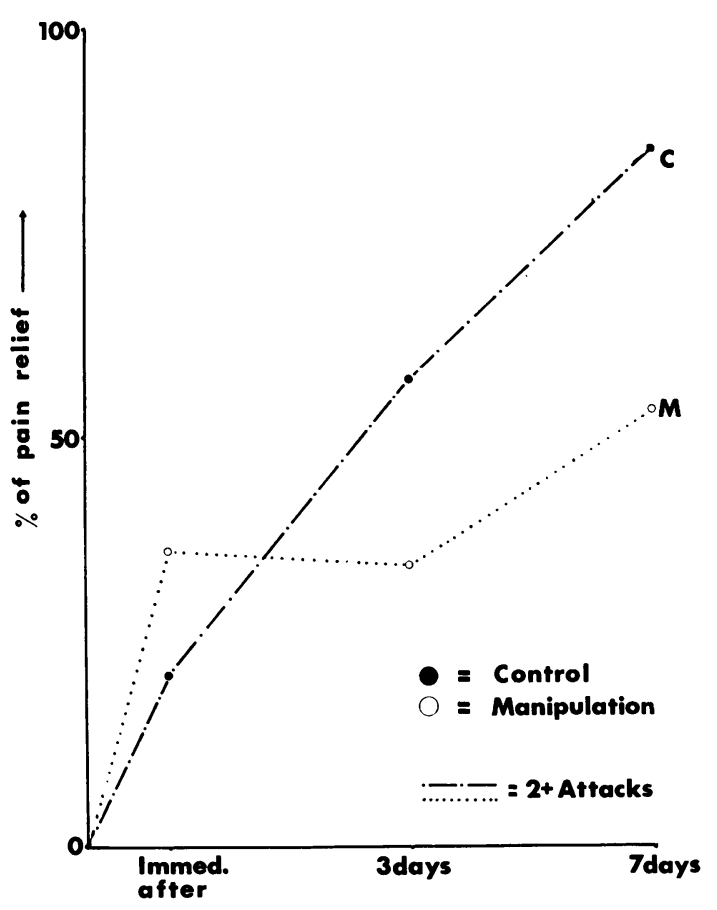

FIG. 3. Patients in their second or subsequent attacks whose pain had lasted seven days or more at the time of treatment (Table 2, lines 7 and 8 ).

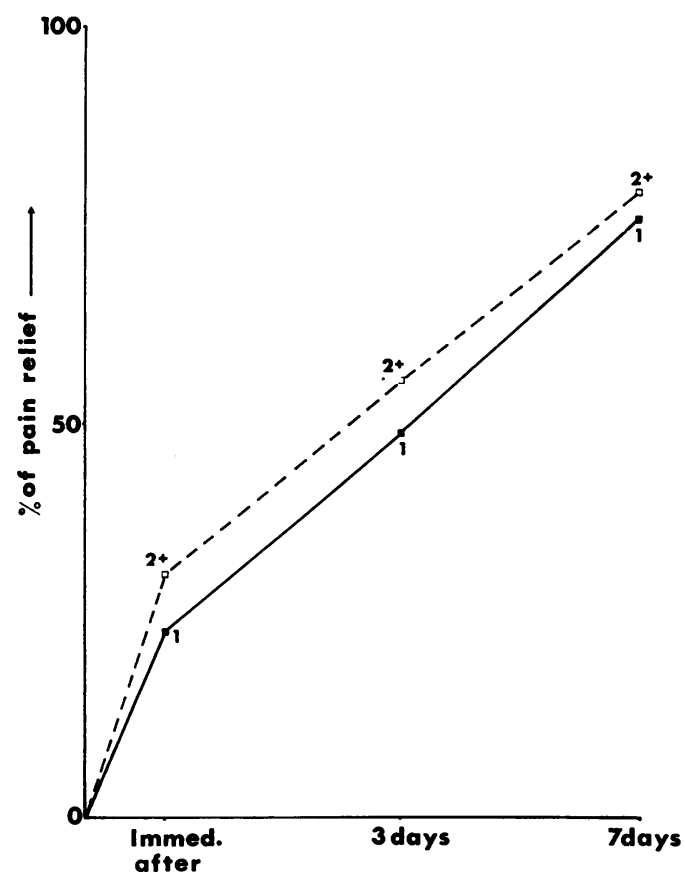

FIG. 4. First attack of pain compared with second and subsequent attacks in control and manipulated groups combined (Table 2, lines 1, 2, 3, 4, and 5, 6, 7, 8). 


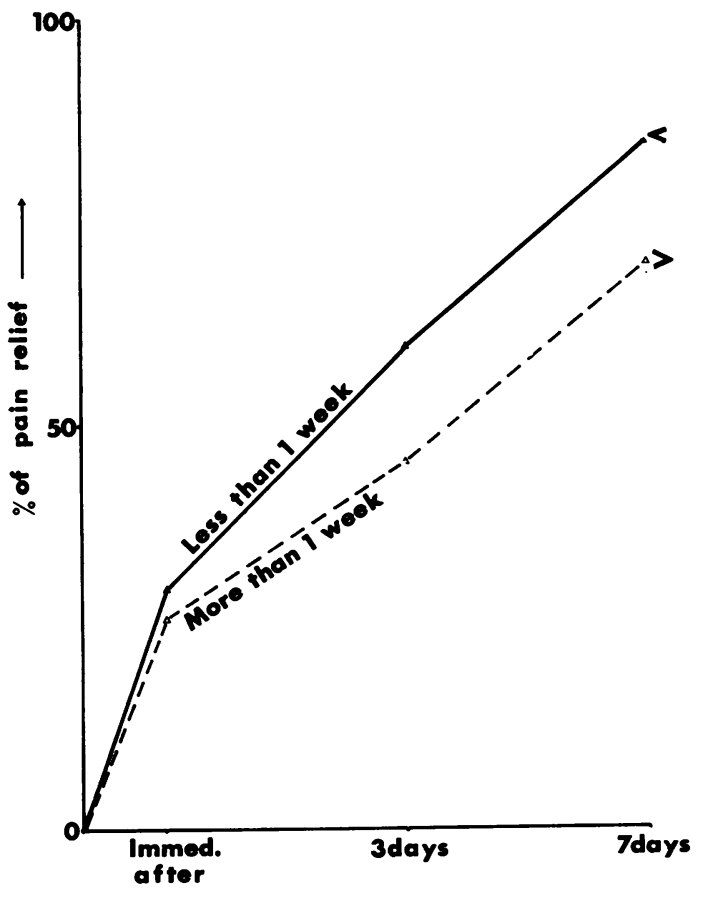

FIG. 5. Relief of pain in patients in whom it had lasted for less than seven days at the time of treatment compared with patients who had had pain for seven or more days. Control and manipulated groups combined (Table 2, lines $1,2,5,6$, and $3,4,7,8$ ).

ences were performed in the above comparisons by a nonparametric Mann-Whitney test (Siegel, 1956).

To see if there was some factor other than treatment by manipulation that was important in the prognosis of the back pain, all the results from manipulated patients and controls were pooled and graphed in two ways. Firstly (Fig. 4), pain in patients suffering their first attack appeared to clear more slowly than pain in patients in their second or subsequent attacks (not statistically significant). Secondly (Fig. 5), those with less than a week's history of back pain improved more rapidly than those with more than a week's history of back pain, but again this difference is not statistically significant.

\section{Discussion}

Apart from a slight immediate improvement after treatment there appeared to be no other benefit from manipulation in this trial. It is puzzling to understand why both the untreated and treated groups started to improve immediately after entry to the trial, no matter whether their back pain had lasted for 15 minutes or one month. It can only be assumed that one or more of the following factors common to both groups was of immediate therapeutic value:

(1) coming to a research unit investigating, and therefore intensely interested in, back pain;

(2) having a careful history taken;

(3) being examined thoroughly over the lower limb for neurological signs of nerve root pressure;

(4) having anteroposterior and lateral lumbar radiographs taken, and being told the result at the time of the consultation;

(5) being reassured that there were no neurological signs of spinal tumour, prolapsed intervertebral disc or other disease of the vertebral column;

(6) receiving localized treatment, namely, manipulation or simulated short-wave diathermy; and

(7) being told to go back to work and that the pain would soon improve.

It is unreasonable to deduce from these results that manipulation can play no part in the treatment of back pain, because this trial does in fact show that manipulation gives significantly more pain relief than the control 'treatment' in the first 15 minutes after the first session on the first day. Perhaps if patients had been given five daily manipulation sessions their improvement might have been greater by the end of the week. Another point is that the graphs show averaged results, some patients being made better by manipulation and others being made worse by manipulation. For example, one patient in the control series, at the one-month follow-up, said he was free from pain for the first time in five years.

By examining a larger series of cases it might be possible to establish criteria that would determine, before treatment, which patients would be improved, be made worse, or remain unaffected, by manipulation; for example, all the patients in this series under 26 years of age were completely better by the end of the first week, whether they were manipulated or not. On the whole, these patients presented as mild cases of back pain, and in order to establish the therapeutic value of manipulation it would be necessary to carry out larger scale trials in the very acute and very painful cases, as well as in cases that had been refractory to other forms of treatment for at least three months.

This trial was part of a back pain project supported by a generous grant from the Nuffield Foundation which covered the salaries of J. R. G. and J. G. M. We would like to thank also Professor Sir Herbert Seddon and Mr. P. H. Newman, who helped and criticized the work at every stage; Dr. Ian Sutherland of the MRC Statistical Research and Service Unit, who designed the original statistical framework of the trial; Mr. N. G. Cadman, Works Director and Manager of the Westinghouse Brake \& Signal Company, for his constant help; and Sister R. E. Parks and her staff, who bore the extra burden of work caused by the clinical trial. 


\section{References}

British Association of Physical Medicine (1966). Pain in the neck and arm: a multicentre trial of the effects of physiotherapy. British Medical Journal, 1, 253-258.

Glover, J. R. (1960). Back pain and hyperaesthesia. Lancet, $1,1165-1169$

(1966). A clinical trial of rotational manipulation of the spine in back pain cases occurring in a factory. Proceedings of the Royal Society of Medicine, 59, 847-848.

Siegel, S. (1965). Nonparametric Statistics for the Behavioral Sciences (International Student Edition). McGraw-Hill, London.

Received for publication August 22, 1972.

Accepted for publication August 21, 1973. 